\title{
On the Linkage between Labrador Sea Water Volume and Overturning Circulation in the Labrador Sea: A Case Study on Proxies ${ }^{\mathscr{D}}$
}

\author{
FEILI Li AND M. SUSAN LOZIER \\ Earth and Ocean Sciences, Nicholas School of the Environment, Duke University, Durham, North Carolina
}

(Manuscript received 13 October 2017, in final form 1 April 2018)

\begin{abstract}
Although proxies have generally been used to study deep ocean convection and overturning circulation in the Labrador Sea, their efficacy has not been explicitly evaluated because observations that directly measure those variables are scarce. In this study, the volume of newly formed Labrador Sea Water (LSW) and the overturning circulation in the Labrador Sea are estimated using observational data and output from a highresolution ocean model and then compared to proxies used to represent those variables. The comparisons reveal the limitations of proxies, highlighting the desirability of robust estimates derived from direct monitoring in the region [i.e., from Argo and Overturning in the Subpolar North Atlantic Program (OSNAP)]. A linkage among LSW formation, overturning circulation in the Labrador Sea, and the export of LSW from the basin on interannual time scales is found in the model.
\end{abstract}

\section{Introduction}

The Labrador Sea is one of only a few locations in the World Ocean that is home to open ocean convection with mixed layer depths (MLDs) exceeding $1000 \mathrm{~m}$ during harsh winters (Fig. 1). Convection in this basin produces an intermediate water mass known as Labrador Sea Water (LSW; Lazier 1980). LSW, formed in the interior of the Labrador Sea and within the western boundary current rimming this basin (Pickart et al. 2002; Palter et al. 2008), is characterized by low temperature, salinity, and potential vorticity (PV) (e.g., Talley and McCartney 1982). After its formation, LSW is exported out of the Labrador Sea following two main pathways (Lavender et al. 2000; Fischer and Schott 2002; Straneo et al. 2003): one is the deep southeastward-flowing western boundary current (DWBC) off the Labrador slope, and the other is a cyclonic interior route into the central Irminger Sea. Although newly formed LSW leaves the Labrador Sea fairly quickly via these routes (Straneo et al. 2003; Lavender et al. 2005), its subsequent export to the subtropics is on the order of years

Supplemental information related to this paper is available at the Journals Online website: https://doi.org/10.1175/JCLI-D-170692.s1.

Corresponding author: Feili Li, feili.li@duke.edu to decades (Fischer and Schott 2002; Lozier et al. 2013; Zou and Lozier 2016).

Numerous modeling studies have suggested that convective variability in the Labrador Sea on multiannual to decadal time scales drives the variability in the meridional overturning circulation (MOC) in the Labrador Basin itself, as well as within the entire North Atlantic basin [Kuhlbrodt et al. (2007) and references therein]. However, there has been no observational evidence to date to confirm this linkage (Lozier 2012). In large part, this lack of confirmation stems from the fact that there have been no direct measures of the overturning circulation in the Labrador Basin, much less in the broader subpolar North Atlantic, nor have there been direct estimates of the volume of deep water formed each winter. As a result, oceanographers have used proxies for the volume of deep water produced (e.g., Yashayaev 2007; Yashayaev et al. 2007) and the overturning variability (e.g., Zhang 2008; Jackson et al. 2016; Robson et al. 2016). The use of proxies, however, has not been without problems. For example, estimates of LSW formation that relied on different methods and assumptions span a factor of about 6 during the period of deep convection in the early 1990s (Haine et al. 2008).

In the near future, however, observations from a new monitoring system installed in 2014 in the subpolar region [Overturning in the Subpolar North Atlantic Program (OSNAP); Lozier et al. 2017] will allow for a closer 
study of the relationship between these variables. The western leg of OSNAP (OSNAP West; see Fig. 1 for location) consists of arrays over the continental slopes bracketing the Labrador Basin. Data from the OSNAP West array, along with profiling floats from the International Argo Program (http://www.argo.ucsd.edu) and satellite altimetry ( $\mathrm{Li}$ et al. 2017), will produce a direct and continuous estimate of the overturning variability in the Labrador Sea (Lozier et al. 2017). Similarly, as will be demonstrated in this paper, the density of Argo floats now available allows for a direct estimate of the volume of deep water formed each winter in the Labrador Basin (see also Holte and Straneo 2017).

Nevertheless, the need for proxies will continue. The first estimate of the overturning circulation from the OSNAP program, expected in the spring of 2018, will cover the observational period from August 2014 to April 2016. We cannot expect to ascertain the linkage between deep water formation variability and overturning variability from a sample of two winters. However, the observations will inarguably provide important ground truth for model estimates, which are readily available over a much longer temporal period. Furthermore, the observational estimates will, in time, also allow us to explore the use of proxies for the long-term monitoring of the overturning circulation. OSNAP is a resource-intensive program. As such, a stated goal of the program is to develop a cost-efficient long-term monitoring system, which may be a proxy measure. So, we are in an interesting period: we have used proxies to date and will likely rely on proxies in the future, but in the intervening period, we will have OSNAP data to test those proxies.

The goal of this paper is twofold: 1) to lay the groundwork for the use of proxies for the volume of newly formed LSW and the overturning circulation in the Labrador Sea and 2) to investigate relationships that will be tested once OSNAP data become fully available. Using a combination of observational and model data, we are focused on evaluating the existing proxies for capturing the variability of the LSW volume and overturning circulation in the Labrador Sea. We then evaluate the linkage between LSW formation variability and overturning variability within the basin based on highresolution ocean model output. The paper is organized as follows. Section 2 reviews the LSW volume and overturning proxies to be evaluated; section 3 introduces the data used in this study and describes our methods for reproducing proxies, calculating overturning transports, and estimating LSW volume and transport; section 4 evaluates the effectiveness of proxies for capturing convective and overturning variability; and section 5 describes the relationship between LSW formation and the MOC in the Labrador Sea from an eddy-resolving ocean model. The paper is summarized in section 6 .

\section{Background}

Below, we describe proxies that will be examined in this study to represent either the volume of LSW produced each winter or the strength of overturning in the Labrador Sea.

\section{a. Proxy for wintertime $L S W$ volume}

Hydrographic sections along the AR7W line across the Labrador Sea have been occupied during Fisheries and Oceans Canada's (DFO's) annual survey, as part of the World Ocean Circulation Experiment (WOCE), then the Climate Variability and Predictability Project (CLIVAR), and presently the Atlantic Zone Off-Shelf Monitoring Program (AZOMP). The repeat section is typically conducted in late spring/early summer from the Canadian continental shelf toward Greenland, which uniquely provides an annual record of the hydrographic conditions in the Labrador Sea (Lazier et al. 2002). Based on temperature and salinity profiles from all fulldepth CTD casts from each year's survey, a sectionmean LSW layer thickness is derived, which is multiplied by a spatial area, held constant for all years, to yield a measure of the LSW volume for each year (Yashayaev 2007; Yashayaev et al. 2007; Yashayaev and Loder 2017). Among all observational efforts, this LSW volume estimate, or proxy, has been made most consistently over the past decades and has been analyzed to discuss variability in LSW formation, depletion, and accumulation in the Labrador Sea (e.g., Yashayaev 2007). However, in these studies, there is an implicit assumption that the LSW layer thickness at AR7W in spring reflects LSW volume production the previous winter. This underlying assumption has not yet been verified due to the paucity of fullbasin hydrographic measurements in the Labrador Sea.

\section{b. Dynamic proxy for overturning variability}

Downstream of the main convection site, a current meter array has been deployed near the exit point of the Labrador Sea, at 53N, since 1997 (Fischer et al. 2004; see Fig. 1 for location). Current meter records from this array have been used to calculate the magnitude and variability of LSW transport along the western boundary (Fischer et al. 2004; Dengler et al. 2006; Zantopp et al. 2017). That observed transport variability has, in some prior studies, been presumed to reflect the change in LSW formation in the basin (e.g., Eden and Willebrand 2001; Böning et al. 2006). However, in contrast to this expectation, the boundary current transport at $53^{\circ} \mathrm{N}$ does not clearly reflect changes in convection 

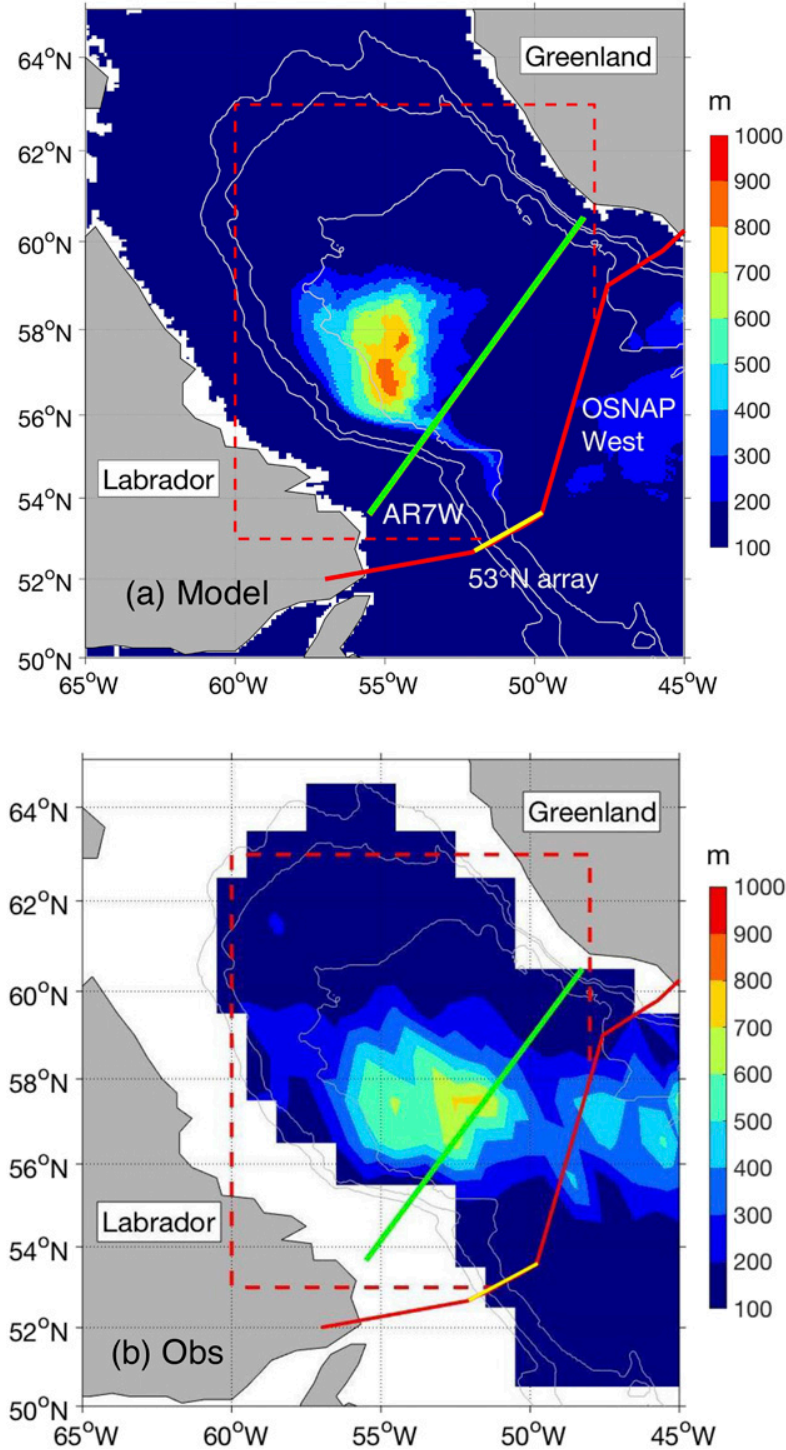

FIG. 1. (a) Winter (JFM) mean MLD from the model used in this study for 1990-2004. MLD is calculated as the depth at which the potential density (referenced to the surface) changes by $0.03 \mathrm{~kg} \mathrm{~m}^{-3}$ from the value at $10 \mathrm{~m}$. Red, yellow, and green solid lines indicate the OSNAP West section, the $53^{\circ} \mathrm{N}$ array, and the AR7W section, respectively. Red dashed lines, together with the OSNAP West line, indicate the area used for calculating LSW volume and surface heat loss. Gray contours indicate the 1000-, 2000-, and 3000-m isobaths. (b) As in (a), but from Argo-derived monthly MLD climatology (Holte et al. 2017a) using the "density algorithm mean MLD" method (Holte et al. 2017b).

intensity associated with LSW formation from the late 1990s to 2000s (Dengler et al. 2006; Fischer et al. 2010). Based on a historical reconstruction of boundary current transport for 1949-99, Myers and Kulan (2012) suggest a delayed response of the transport to periods of strong deep convection over decadal time scales. Collectively, these studies have cast doubt on the assumed linkage between changes in the boundary current transport observed at $53^{\circ} \mathrm{N}$ and overturning variability in the region on interannual to decadal scales (e.g., Lozier 2012).

\section{c. Thermodynamic proxies for overturning variability}

Several prior studies have suggested that property variability at high latitudes can be used to assess overturning variability in the low- to midlatitude North Atlantic. Using a global ocean reanalysis product, Jackson et al. (2016) found that density changes in the deep Labrador Sea (1000-2000 m) lead density and overturning changes at $26.5^{\circ} \mathrm{N}$ by a couple of years. Similarly, from an analysis of observations and data from a climate model, Robson et al. (2016) suggested that a reduction in density at depths of $1000-2500 \mathrm{~m}$ in the Labrador Sea is linked to the recent MOC decline at $26.5^{\circ} \mathrm{N}$. Furthermore, from a 1000-yr coupled ocean-atmosphere model simulation, Zhang (2008) suggested that subsurface temperature $\left(t_{\text {sub }}\right)$ across a broad extratropical North Atlantic region could be used as a proxy for overturning changes in the region (the so-called MOC fingerprint). This latter proxy is obtained from an empirical orthogonal function (EOF) analysis of annual $t_{\text {sub }}$ anomalies (at $400 \mathrm{~m}$ ) in the domain $20^{\circ}-65^{\circ} \mathrm{N}, 80^{\circ} \mathrm{W}-0^{\circ}$. The authors showed that the first principal component (PC1) of the $t_{\text {sub }}$ time series is highly correlated with the MOC at $40^{\circ} \mathrm{N}(r=0.81$ with zero time lag). We note that each of these studies uses proxies for overturning changes in the subtropical North Atlantic. Therefore, given the lack of meridional coherence in the overturning variations across the North Atlantic (Bingham et al. 2007; Biastoch et al. 2008; Lozier et al. 2010; Zhang 2010), the extent to which those proxies represent overturning variability in the subpolar region and in the Labrador Sea in particular is unclear. Furthermore, it is also unclear whether these measures are adequate proxies for overturning variability at subtropical latitudes in other models.

\section{Data and methods}

The spatial domain of our analysis is northwest of the OSNAP line in the Labrador Sea, an area demarcated in Fig. 1, along with the AR7W line. Various datasets used in this study are described below, followed by a detailed description of the calculation methods for key variables that will be discussed in section 4 .

\section{a. Observations}

\section{1) HYDROGRAPHIC DATA}

We use observations in sections $3 \mathrm{c}$ and $3 \mathrm{~d}$ for model validation and in section $4 \mathrm{a}$ to obtain independent 

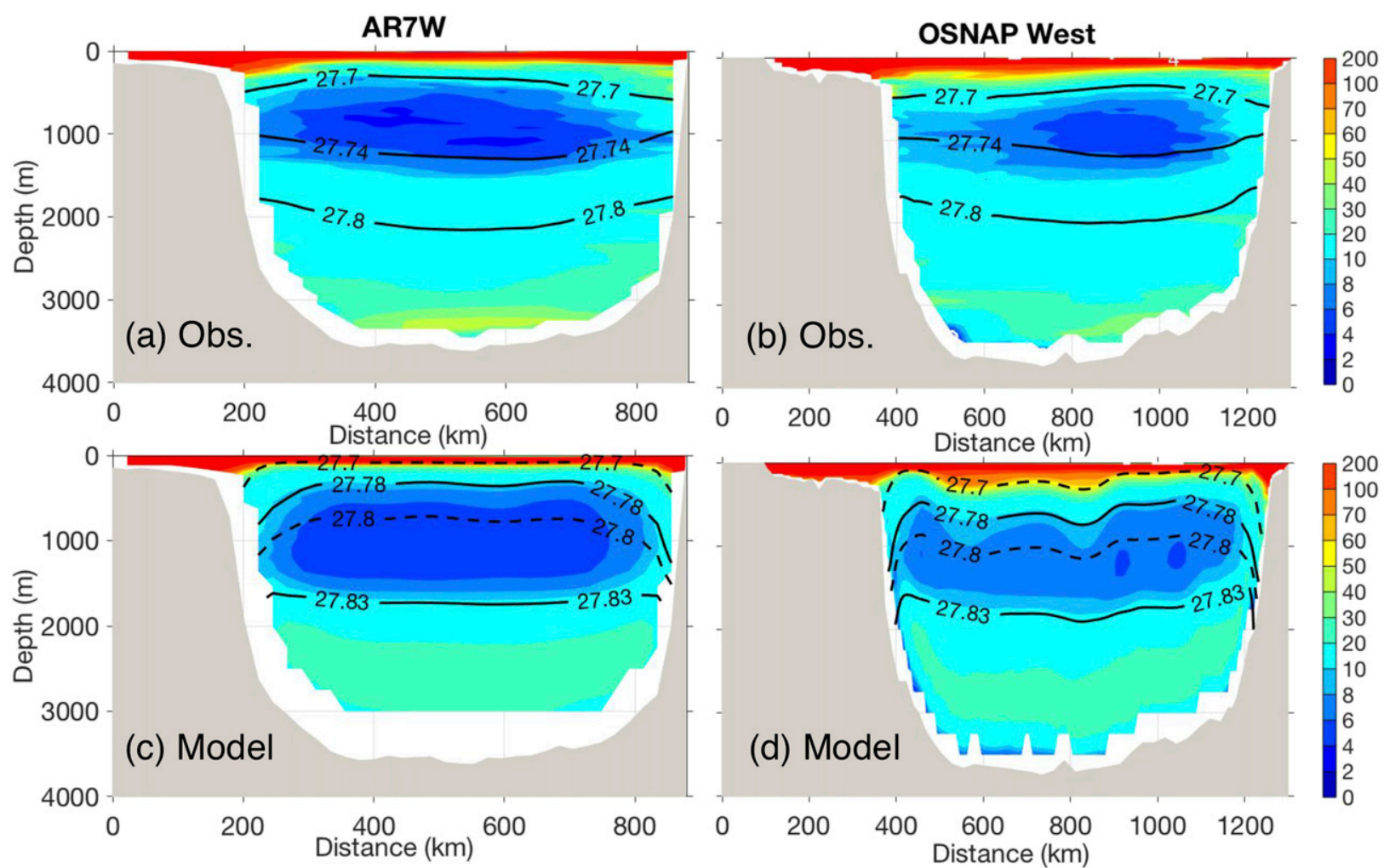

FIG. 2. Monthly mean PV $\left(10^{-12} \mathrm{~m}^{-1} \mathrm{~s}^{-1}\right)$ on the (a) AR7W and (b) OSNAP West sections for 2003-13, derived from the Argo-based OA product. Isopycnals $\left(\mathrm{kg} \mathrm{m}^{-3}\right)$ are indicated with black lines. (c),(d) As in (a),(b), but from model output for 1990-2004. Solid black lines denote the LSW density limits used for the model diagnostics.

estimates of LSW layer thickness and LSW volume. The observational datasets used in this study are

(i) Full-depth temperature and salinity profiles from DFO's annual CTD survey of AR7W between 2003 and 2013, downloaded from the Carbon Dioxide Information Analysis Center (CDIAC; http://cdiac. esd.ornl.gov/). The AR7W survey was conducted in May of all years except for 2003 (July) and 2012 (June) (Table S1 of the online supplemental material).

(ii) Argo temperature and salinity profiles for the upper $2000 \mathrm{~m}$ in the Labrador Sea, with quality flag of 1 (good) or 2 (probably good) from 2003 to 2013, downloaded from the U.S. Global Ocean Data Assimilation Experiment (USGODAE) Argo DAC (http://www.usgodae.org/argo/argo.html; data accessed on 16 October 2017). In addition to the quality flags, the gray list of Argo floats (https://www. nodc.noaa.gov/argo/grey_floats.htm) was used to reject all problematic data. Profiles having no salinity records were also rejected. As part of this study, we directly compare a measure of LSW volume derived from AR7W CTD data with that derived from Argo data. Thus, we use Argo data only in the overlap period for these two datasets (2003-13).

(iii) World Ocean Atlas 2013 (WOA13) temperature (Locarnini et al. 2013) and salinity (Zweng et al. 2013) data at $1 / 4^{\circ}$ by $1 / 4^{\circ}$ resolution downloaded from the NOAA National Oceanographic Data Center (NODC; https://www.nodc.noaa.gov/).

\section{2) ANALYZED FIELDS}

We use an objective analysis (OA) method (Bretherton et al. 1976; Hadfield et al. 2007) to produce (i) monthly 2D gridded density fields on the OSNAP West and AR7W sections (see Fig. 1 for location) and (ii) monthly 3D gridded density fields covering the central Labrador Sea (polygon in Fig. 1). Gridded density fields are used for calculating LSW layer thickness (sections $3 \mathrm{c}$ and 4a; Figs. 3, $5,6)$ and for calculating the volume of newly formed LSW in the Labrador Sea (sections 3c and 4a; Figs. 3, 5). These OA fields are also used for validating the model (section $3 \mathrm{c}$ and Fig. 2).

The input for the OA is Argo and WOA13 data, both mentioned above. There are, on average, 69 Argo profiles in the Labrador Sea $\left(53^{\circ}-63^{\circ} \mathrm{N}, 59^{\circ}-45^{\circ} \mathrm{W}\right)$ each 
month for 2003-13. The number of available Argo profiles was particularly limited near the beginning of the Argo period (fewer than 20 in 2003) but has gradually increased with time (about 120 in 2013; Fig. S1). For the cross-sectional OA product, a grid is defined both at AR7W and OSNAP West, with a horizontal resolution of $1 / 4^{\circ}$ and a changing vertical resolution from $5 \mathrm{~m}$ at the surface to $100 \mathrm{~m}$ at depth. For the gridded OA product, we adopt the same grid as WOA13, which has a horizontal resolution of $1 / 4^{\circ}$ by $1 / 4^{\circ}$ and 102 levels in the vertical with changing intervals from $5 \mathrm{~m}$ at the surface to $100 \mathrm{~m}$ at depth. Since Argo profiles provide only temperature and salinity data for the upper $2000 \mathrm{~m}$ in the water column, data below $2000 \mathrm{~m}$ are filled directly with climatology. The reader is referred to Li et al. (2017) for more details on OA implementation and validation. We also present additional validation in section $3 \mathrm{c}$.

\section{b. Model output}

Model output from a primitive equation, $z$-coordinate regional ocean general circulation model (OGCM) of the North Atlantic (from $18^{\circ} \mathrm{S}$ to $70^{\circ} \mathrm{N}$ ) is used in this analysis. The model is based on a modified version of the Modular Ocean Model (MOM2.1; Pacanowski 1996) that was developed for studying circulation in the Atlantic Ocean [Family of Linked Atlantic Model Experiments (FLAME)] (Eden and Willebrand 2001; Böning et al. 2006; Biastoch et al. 2008). A suite of simulations from the FLAME hierarchy with varying spatial resolution has been used for studying deep ocean convection (Böning et al. 2003) and eddy variability (Eden and Böning 2002; de Jong et al. 2016) in the Labrador Sea; subpolar gyre (SPG) transport variability (Böning et al. 2006); pathways of the deep limb of the MOC (Gary et al. 2011; Lozier et al. 2013); and southward propagation of MOC anomalies (Getzlaff et al. 2005; Biastoch et al. 2008). We use model output from the highest member of the FLAME ensemble, which has a horizontal resolution of $1 / 12^{\circ}$ (longitude) by $1 / 12^{\circ} \cos (\phi)$ (where $\phi$ is latitude), 45 levels in the vertical with changing intervals from $10 \mathrm{~m}$ at the surface to $250 \mathrm{~m}$ at depth, and isopycnal mixing schemes with the addition of a bottom boundary layer (Beckmann and Döscher 1997). The model was initially run with 10 years of ECMWF climatological forcing and then forced by monthly flux anomalies computed from the NCEPNCAR reanalysis data (Kalnay et al. 1996) spanning 1990-2004. To allow for important exchange processes across the boundaries, climatological temperatures and salinities are maintained at the open boundaries, and sea surface salinities are restored to monthly climatology on a time scale of 15 days. The normal component of the barotropic velocity at the southern boundary is prescribed according to the Sverdrup relation, while the barotropic flow at the northern boundary is given by the results from an Arctic Ocean model (Brauch and Gerdes 2005). Monthly mean property and velocity for 1990 2004 were stored as output. Model data are linearly interpolated (inverse distance weighting) to a crosssectional grid on the OSNAP line (with the horizontal and vertical resolution native to the model). The interpolated model data are used to identify an appropriate LSW definition in the model (section 3c) and to calculate the volume transport at $53^{\circ} \mathrm{N}$ and across the OSNAP section (section 3d).

\section{c. Modeled and observed LSW thickness and volume}

\section{1) Definition of LSW}

The observed density and PV fields across the AR7W and OSNAP West sections clearly show an LSW layer, identified as the low-PV waters located between $\sim 500$ and $1500 \mathrm{~m}$ and between the isopycnals 27.70 and $27.80 \mathrm{~kg} \mathrm{~m}^{-3}$ (Figs. 2a,b). As mentioned earlier, the monthly mean density field at those sections is obtained from an OA product that incorporates Argo and WOA13 data. The upper density limit of LSW is lighter, compared to what has been traditionally used (e.g., $27.74-27.80 \mathrm{~kg} \mathrm{~m}^{-3}$ for observed LSW; Stramma et al. 2004), owing to the production of less dense LSW in the 2000s (e.g., Kieke and Yashayaev 2015). In the model, there is a similar area of low PV between $\sim 500$ and $1500 \mathrm{~m}$ across the sections (Figs. 2c,d). However, the isopycnals used to define LSW in the observations $\left(27.70-27.80 \mathrm{~kg} \mathrm{~m}^{-3}\right)$ are clearly too shallow to define LSW in the model (black dashed lines in Figs. 2c,d). Instead, the isopycnals $27.78-27.83 \mathrm{~kg} \mathrm{~m}^{-3}$ are used to define LSW in the model throughout this study, since these isopycnals bound that area of low PV, an indicator of a recently convected water mass.

\section{2) LSW THICKNESS CALCULATION}

We calculate the section-mean LSW layer thickness at AR7W from full-depth CTD data collected during each annual AR7W occupation, after Yashayaev et al. (2007):

(i) The thickness of each $0.01 \mathrm{~kg} \mathrm{~m}^{-3} \sigma_{2}$ (potential density referenced to $2000 \mathrm{dbar}$ ) layer in the range of $36.80-36.98 \mathrm{~kg} \mathrm{~m}^{-3}$ is constructed for any CTD profile with a bottom depth $>3300 \mathrm{~m}$ and within $150 \mathrm{~km}$ of the AR7W line. First, at each station, we determine the exact depth of each $\sigma_{2}$ surface by interpolating from the closest two density surfaces above and below, obtained from the CTD profile. The interpolation is performed on isobars with a vertical interval of $0.5 \mathrm{dbar}$ between the closest 


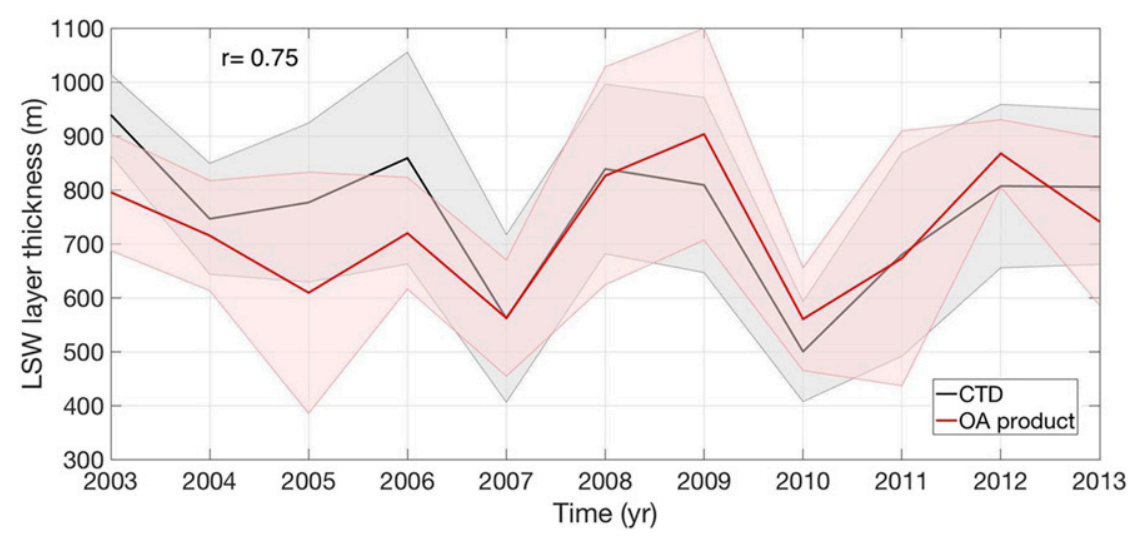

FIG. 3. The section-mean LSW layer thickness on the AR7W section inferred from the CTD data (black) and the Argo-based OA product (red) during the same months. Shading indicates spatial variations of the section means (one standard deviation).

two density surfaces. Then we calculate the distance between adjacent $\sigma_{2}$ surfaces to yield a thickness (m).

(ii) The section-mean thickness of each density interval is obtained by averaging the layer thicknesses in that density interval at all stations, with the average weighted by area representation.

(iii) A core isopycnal of LSW is determined first as the density that corresponds to the peak layer thickness. Then, the LSW layer is defined by the $\sigma_{2}$ isopycnals within $\pm 0.017 \mathrm{~kg} \mathrm{~m}^{-3}$ of the core isopycnal.

The above steps were performed for all surveys between 2003 and 2013 to yield an annual time series of LSW layer thickness. On average, the 2003-13 mean LSW layer thickness at AR7W is $756 \pm 130 \mathrm{~m}$, with significant interannual variations (black line in Fig. 3).

In addition, we provide an independent estimate of the section-mean LSW layer thickness using the OA product. The calculations follow the same steps described above. As a validation of the OA method, we compared the PV fields at AR7W obtained from the OA product to those from the CTD data and found a favorable match, even at the beginning of the Argo period (Fig. S2). The LSW layer thickness from the OA product $(725 \pm 117 \mathrm{~m})$ also matches well with that derived from the CTD data for the overlap period 2003-13. The comparison is also favorable in terms of variability $(r=0.75$; Fig. 3).

\section{3) LSW VOLUME CALCULATION}

For our calculation of newly formed LSW volume, we use both PV and density constraints to define this water mass. Assuming relative vorticity is small, compared to planetary vorticity, PV is approximated as

$$
\mathrm{PV}=f \frac{N^{2}}{g}\left(\mathrm{~m}^{-1} \mathrm{~s}^{-1}\right),
$$

where $f$ is the Coriolis parameter, $g$ is the acceleration due to gravity, $N$ is the Brunt-Väisälä frequency $[(-g / \sigma)$ $(\delta \sigma / \delta z)]$, and $\sigma$ is the potential density referenced to the surface. In the model, newly formed LSW is defined as the water mass in the density range of 27.78 $27.83 \mathrm{~kg} \mathrm{~m}^{-3}$, with $\mathrm{PV}<4 \times 10^{-12} \mathrm{~m}^{-1} \mathrm{~s}^{-1}$, the same PV threshold used by Talley and McCartney (1982). When using observational data instead of model output to evaluate LSW volume, we use the density limits 27.70 $27.80\left(\mathrm{~kg} \mathrm{~m}^{-3}\right)$, as discussed above, yet the same PV constraint is applied. Given a 4-5-yr residence time for LSW in the Labrador Basin (Lazier et al. 2002; Straneo et al. 2003), LSW formed in the previous year or years will be considered part of the newly formed LSW as long as it shares the low-PV signature (e.g., Zou and Lozier 2016).

The observed volume of newly formed LSW in the Labrador Sea is calculated with the OA product as follows. First, the gridded density fields are searched to find all grids that satisfy the density and PV constraints discussed above. The volume of all grids that meet these constraints is summed to yield the total volume of newly formed LSW in the Labrador Sea (see polygon in Fig. 1) for each month. We believe that this estimate of LSW volume has an advantage over previous estimates in that it captures variability in both the vertical and lateral extent of the newly formed water mass.

Next, we focus on the individual month with the maximum LSW volume during each winter [DecemberMarch (DJFM)] in order to study the interannual variability of this water mass. From the OA product, the 2003-13 mean winter maximum LSW volume is $(2.25 \pm$ $0.33) \times 10^{14} \mathrm{~m}^{3}$, ranging from a minimum of $1.7 \times 10^{14} \mathrm{~m}^{3}$ 
in the winter of 2007 to a maximum of $2.9 \times 10^{14} \mathrm{~m}^{3}$ in the winter of 2008. We note that each winter's maximum LSW volume occurs in the month of March.

The modeled LSW volume in the Labrador Sea is calculated based on monthly mean model density fields, following the same steps described above. The mean winter maximum LSW volume is $(1.48 \pm 0.76) \times 10^{14} \mathrm{~m}^{3}$ during the model's temporal domain (1990-2004). The model appears to produce a smaller LSW volume, compared to that observed. However, the model reproduces the interannual variability in the LSW volume. During the early 1990s (1990-95), a period of consistently strong convection (e.g., Lazier et al. 2002), the average magnitude of the modeled LSW volume was $50 \%$ above the mean of all winter maxima. After 199596, LSW volume decreased in magnitude in the model, with some years having only about $1 / 3$ of the volume of that in the early 1990s. These changes in the modeled LSW volume during 1990-2004 are consistent with previous studies based on observations (e.g., Lazier et al. 2002; Kieke and Yashayaev 2015) and numerical models (e.g., Böning et al. 2006).

As a validation of the OA method, we compared the model LSW volume, calculated based on the full model density fields, to one calculated from model density fields at a reduced spatial resolution $\left(1 / 4^{\circ}\right.$ by $\left.1 / 4^{\circ}\right)$. This latter field was obtained via our OA method, using simulated Argo profiles and model climatology as input. To simulate Argo profiles, we randomly selected 69 model density profiles $(0-2000 \mathrm{~m}$ only) within the domain $\left(53^{\circ}-63^{\circ} \mathrm{N}, 59^{\circ}-45^{\circ} \mathrm{W}\right)$ for each month between 1990 and 2004. This monthly number of profiles reflects the average number of actual Argo profiles within the same domain available for each month between 2003 and 2013. The winter maximum LSW volume from the model-based OA product matches well with that calculated using the full model data fields for 1990-2004 $(r=0.94$; root-mean-square difference $=0.28 \times 10^{14} \mathrm{~m}^{3}$; Fig. S3). We also used only 12 simulated density profiles for each month instead of 69 to match the lower limit of Argo data availability at the beginning of the Argo period. The resultant LSW volume time series still reproduces about $70 \%$ of the total variance. We ran three simulations using 12 randomly selected profiles and found similar results (Fig. S3). Although both overestimation and underestimation can occur with the OA product, we note that there is a tendency toward underestimation due to the limited number of profiles available during periods of very large LSW volume (i.e., 1990-93). Overall, we conclude that our OA products are sufficient to provide a robust estimate of the variables of interest.

\section{d. LSW transport and MOC}

\section{1) LSW TRANSPORT CALCULATION}

LSW volume transport is calculated as the transport of water between the bounding isopycnals defining LSW (transport and velocity in this study are positive poleward). With this definition, we are allowing for all water between those density limits to be considered as LSW, regardless of the water's PV. Our calculation of LSW thickness and volume, previously described, is meant to account for only newly formed LSW, whereas the calculation of LSW transport out of the basin is meant to include all LSW, regardless of age.

The first step in calculating the volume transport from the model data is to ascertain the ability of the model to reproduce the mean and variability of the volume transport in the Labrador Sea, especially in the LSW layer. Figure 4 shows a comparison between the observed and modeled structures of the alongshore velocity across the $53^{\circ} \mathrm{N}$ section. The observed boundary current has two distinct cores (two local minima of the velocity; Fig. $4 \mathrm{a}$ ): one near the shelf break at $\sim 20 \mathrm{~km}$ and the other near the base of the continental slope at $\sim 100 \mathrm{~km}$. Away from the slope, there is a relatively narrow northward current (180-240 km), part of a weak recirculating component in the western Labrador Sea (Lavender et al. 2000). While the observed velocity structure is captured well in the model (Fig. 4b), there are a few discrepancies: the upper core of the model boundary current is farther offshore, the deeper core is slightly narrower, and the northward recirculation is located more inshore, all compared to the observations.

Despite these few structural differences, the LSW transport at $53^{\circ} \mathrm{N}$, defined as the sum of southeastward transport in the LSW layer perpendicular to the section, is well reproduced by the model. Here, we calculate the monthly LSW transport along the western boundary across the $53^{\circ} \mathrm{N}$ section ( $\left.T_{\mathrm{LSW} \_ \text {bnd }}\right)$ using model velocity output for 1990-2004. The modeled mean $T_{\text {LSW_bnd }}$ is $-13.78 \pm 2.81 \mathrm{~Sv}\left(1 \mathrm{~Sv} \equiv 10^{6} \mathrm{~m}^{3} \mathrm{~s}^{-1}\right)$ for $1990-2004$. The LSW transport is enhanced in winter: the mean of all winter minimums is $-16.99 \pm 3.43 \mathrm{~Sv}$. From seven shipboard ADCP sections, Dengler et al. (2006) reported a mean volume transport in the LSW layer (27.74-27.80 $\mathrm{kg} \mathrm{m}^{-3}$ ) of $-11.30 \mathrm{~Sv}$ during 1996-2005. Over the same months (except for August 2005 since the model only covers through 2004), the modeled mean transport in the LSW layer $\left(27.78-27.83 \mathrm{~kg} \mathrm{~m}^{-3}\right)$ is $-11.85 \pm 2.08 \mathrm{~Sv}$. Most recently, Zantopp et al. (2017) reconstructed an LSW transport time series at $53^{\circ} \mathrm{N}$ based on an extensive mooring effort that is combined with LADCP data. During the overlap period 1997-2004, 

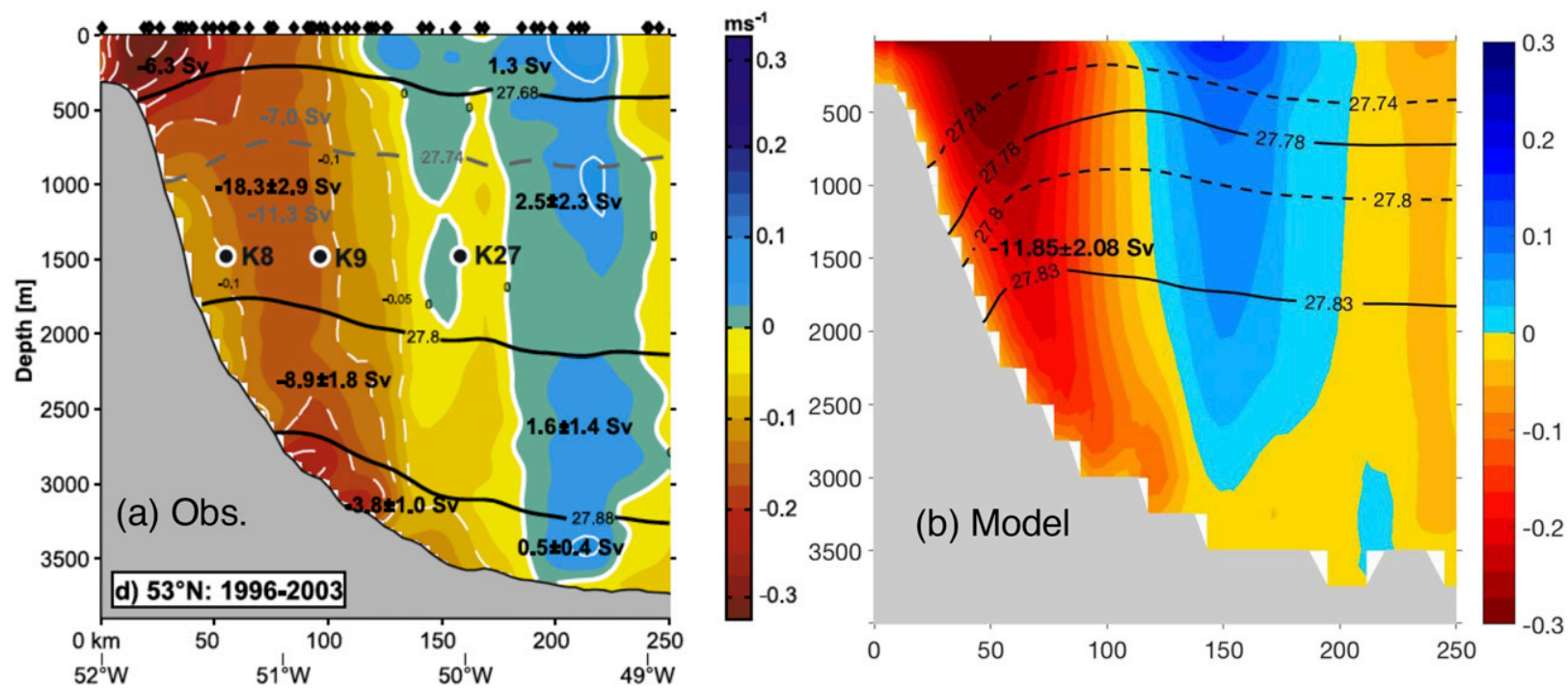

FIG. 4. (a) Observed mean velocity $\left(\mathrm{m} \mathrm{s}^{-1}\right)$ at $53^{\circ} \mathrm{N}$ from seven hydrographic sections during Aug 1996, Jul 1997, Jul 1998, Jul 1999, Jun

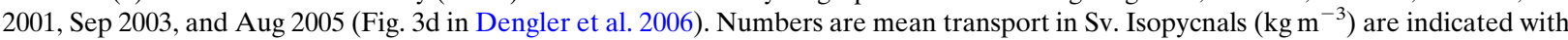
black and gray lines. Black circles show positions of three moorings as part of the $53^{\circ} \mathrm{N}$ array. (b) Model mean velocity ( $\mathrm{m} \mathrm{s}^{-1}$ ) from the same months, except for Aug 2005, which is beyond the model's temporal span (1990-2004). The model velocity has been rotated to the section. Isopycnals $\left(\mathrm{kg} \mathrm{m}^{-3}\right)$ are indicated with black lines (solid lines are the LSW density limits used for the model diagnostics).

the mean LSW transport is similar in the model $(-12.64 \pm 1.47 \mathrm{~Sv})$ and observations [using the mean and standard deviation in density space reported in Zantopp et al. (2017) for each year, the 1997-2004 mean LSW transport is $-15.88 \pm 2.29 \mathrm{~Sv}]$. The modeled LSW transport is also comparable in magnitude to a long-term mean estimate of the transport across $53^{\circ} \mathrm{N}$ from a historical reconstruction [using the mean transport for classical and upper LSW reported in Myers and Kulan (2012), the 1949-99 mean LSW transport is $-9.8 \pm 3.8 \mathrm{~Sv}$ ] and with that observed upstream at the AR7W line (roughly $300 \mathrm{~km}$ north of the $53^{\circ} \mathrm{N}$ array) from LADCP measures [using the estimated transport for each year during five occupations of AR7W in 1995, 1996, 1998, 2001, and 2003 reported in Hall et al. (2013), the mean transport in the 27.74$27.80 \mathrm{~kg} \mathrm{~m}^{-3}$ layer is $-10.4 \mathrm{~Sv}$. Moreover, good agreement is found for the trend in LSW transport. In the model, $T_{\mathrm{LSW} \text { bnd }}$ has weakened since the late $1990 \mathrm{~s}$, showing a linear decline of $2.9 \mathrm{~Sv}$ decade ${ }^{-1}$. Similarly, Zantopp et al. (2017) found a linear trend of $2.6 \mathrm{~Sv}$ decade ${ }^{-1}$ over the full record (1997-2014), which is mostly the result of decreasing transports between 1997 and 2001 since there is only a negligible trend for the rest of the record. Overall, the volume transport, especially in the LSW layer, is well reproduced by the model. Therefore, we consider the model to be a useful tool for examining LSW transport and export variability in the Labrador Sea.

\section{2) MOC CALCULATION}

The MOC is defined as the maximum of the overturning streamfunction in density space $\Psi(\sigma, t)$ at OSNAP West (e.g., Mercier et al. 2015):

$$
\begin{aligned}
\operatorname{MOC}(t) & =\max [\Psi(\sigma, t)] \\
& =\max \left[\int_{\sigma_{\min }}^{\sigma} \int_{x_{w}}^{x_{e}} v(x, \sigma, t) d x d \sigma\right](\mathrm{Sv}),
\end{aligned}
$$

where $v$, the velocity normal to the OSNAP section, is integrated from west $\left(x_{w}\right)$ to east $\left(x_{e}\right)$ and from top to bottom across density surfaces. This MOC definition is used throughout this study, unless otherwise noted. The modeled mean MOC at OSNAP West is $5.21 \pm 1.99 \mathrm{~Sv}$ for 1990-2004. This mean MOC is consistent with that observed from a hydrographic occupation of the OSNAP West section in the summer of 2014 (5.5 Sv; N. P. Holliday 2017, personal communication). The modeled mean MOC is consistent with previous estimates across the AR7W section derived from Argo and Profiling Autonomous Lagrangian Circulation Explorer (PALACE) floats (2.5 Sv; Holte and Straneo 2017) or from summer hydrography and PALACE floats ( $2 \mathrm{~Sv}$; Pickart and Spall 2007). The mean MOC is stronger at OSNAP West because some water masses formed south of the AR7W line are now taken into account. The model MOC is intensified during winter, and the mean 
of the winter maximum $\mathrm{MOC}$ is $8.00 \pm 2.57 \mathrm{~Sv}$, about $50 \%$ above the annual mean. The MOC exhibits strong interannual variability with only weak seasonal variability, in which the seasonal MOC changes explain a small portion $(23 \%)$ of the total variance.

Alternatively, the MOC can be defined as the sum of all transports toward the Labrador Sea from the sectionwidth integrated transport profile (e.g., Li et al. 2017). We refer to the result from this definition as $\mathrm{MOC}_{\text {north }}$. The modeled mean $\mathrm{MOC}_{\text {north }}$ is $12.40 \pm 2.26 \mathrm{~Sv}$ at OSNAP West for 1990-2004. The correlation between the monthly MOC and $\mathrm{MOC}_{\text {north }}$ time series is 0.73 and is increased to 0.89 over interannual time scales. Therefore, using different definitions has only a slight impact on the temporal variability of overturning transport in the Labrador Sea.

In addition to the MOC, we define a net LSW transport across the OSNAP West section $T_{\mathrm{LSW}}$, which is obtained by summing the section-integrated transports in the LSW layer:

$$
T_{\mathrm{LSW}}(t)=\int_{\sigma_{\mathrm{LSW} \_ \text {min }}}^{\sigma_{\mathrm{LSW} \_ \text {max }}} \int_{x_{w}}^{x_{e}} v(x, \sigma, t) d x d \sigma(\mathrm{Sv}),
$$

where $\sigma_{\mathrm{LSW} \text { min }}$ and $\sigma_{\mathrm{LSW} \text { max }}$ correspond to the lower and upper density limits for LSW, respectively. The $T_{\text {LSW }}$ reflects the net export of LSW out of the Labrador Basin, across the OSNAP West section. The modeled mean $T_{\mathrm{LSW}}$ is $-3.50 \pm 2.07 \mathrm{~Sv}$ for $1990-2004$, and $T_{\mathrm{LSW}}$ is also enhanced in winter $(-6.67 \pm 3.32 \mathrm{~Sv})$. As with the MOC, most of the $T_{\mathrm{LSW}}$ variability occurs for interannual time scales; the seasonal changes in $T_{\text {LSW }}$ explain only a small portion $(28 \%)$ of the total variance. For 1990-2004, the model-derived MOC and $T_{\mathrm{LSW}}$ are strongly correlated over monthly $(r=-0.70)$, seasonal $(r=-0.96)$, and interannual time scales $(r=-0.90)$.

\section{Evaluating proxies for LSW volume and MOC}

We now evaluate the efficacy of existing proxies in approximating the strength of LSW formation and the MOC variability in the Labrador Sea.

\section{a. Is LSW layer thickness a proxy for LSW volume?}

Measures of LSW layer thickness derived from CTD stations along AR7W for 2003-13 are limited due to the annual occupation in early spring (section 3a). Therefore, in this section, we rely on the year-round accumulation of Argo data in the basin to more fully examine the use of thickness as a proxy for LSW volume.
Since DFO's annual AR7W survey typically takes place in May, the first question to answer here is how well annual changes in May LSW layer thickness represent annual LSW volume changes. Although not all surveys were in May, we consider May LSW layer thickness for simplicity and consistency. There is not a significant correlation between the OA-derived May LSW layer thickness and the winter maximum LSW volume (Fig. 5). The correlation remains insignificant if the CTD-derived LSW layer thickness is used. Therefore, we conclude that a measure of LSW layer thickness in May is a poor indicator of the amount of LSW formed the previous winter.

We next examine if March LSW layer thickness is instead a good proxy, given that the maximum LSW volume typically occurs in that month. As expected, the March LSW layer thickness exhibits greater interannual variability than the May thickness (Fig. 5); its range is about twice as large as that in May over the 11-yr period of Argo data (2003-13). During the overlap time period, there is a weak correlation between the May and March LSW layer thickness $(r=0.41)$, thus suggesting a considerable erosion of the seasonal ventilation signal between March and May of each year. Not surprisingly, Fig. 5 shows a strong correlation between the March LSW layer thickness at AR7W and the winter maximum LSW volume $(r=0.85)$, consistent with a similar (strong) relationship $(r=0.91)$ found in an eddypermitting model over a much longer time period since the 1960s (Zou and Lozier 2016).

Note that alternatively, we used $\sigma_{1}$ (potential density referenced to $1000 \mathrm{dbar}$ ) values within $\pm 0.01 \mathrm{~kg} \mathrm{~m}^{-3}$ of the core LSW density to calculate the LSW layer thickness at AR7W (see Yashayaev and Loder 2016), and our conclusions above remain valid.

We next examine the spatial variability of LSW layer thickness in the Labrador Sea, with LSW layer thickness at each location in the basin calculated as described in section 3c. The density of the LSW core for each month, determined at AR7W as described above, is used to define an LSW layer at each location in the Labrador Basin for that month. From a map of the standard deviation of the winter maximum LSW layer thickness (Fig. 6), it appears that the largest signal of interannual thickness variability is in the region northwest of the AR7W line. These results suggest that a more complete metric of volume variability from year to year would result from a full-basin measure. Moreover, how well LSW layer thickness represents LSW volume depends strongly on the spatial distribution of LSW in the Labrador Sea. For example, we found a much stronger, but still modest, correlation between May LSW layer thickness at AR7W and LSW volume $(r=0.60)$ in the 


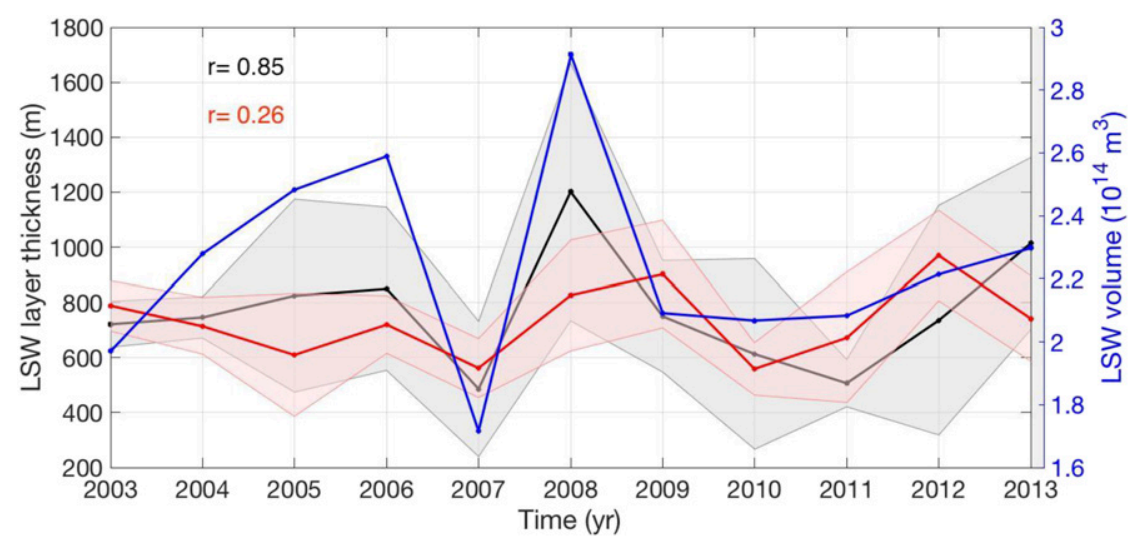

FIG. 5. The winter (DJFM) maximum LSW volume (blue) in the Labrador Sea and the section-mean LSW layer thickness at AR7W in March (black) and May (red) of each year, all from the Argo-based OA product. Numbers are the corresponding correlation coefficient of the LSW layer thickness vs the LSW volume (both are significant at the $95 \%$ level). Shading indicates the spatial variations of the section means (one standard deviation).

model for 1990-2004 (not shown). This increase could be due to strengthened deep convection in the early 1990s that produces a large amount of LSW. Therefore, the use of LSW layer thickness requires care, particularly when it comes to changes in LSW volume during periods of weak deep convection.

Overall, even though the March LSW layer thickness at AR7W, superior to the May LSW layer thickness, serves as an adequate proxy for LSW volume, it is recommended that the LSW volume be directly estimated instead. This direct measure utilizes the same dataset and more fully captures the horizontal and vertical extents of volume changes in the basin.

\section{b. Is western boundary transport in the Labrador Sea a proxy for the MOC in the basin?}

We next evaluate how well the boundary current transport at $53^{\circ} \mathrm{N}$ can represent the overturning circulation in the Labrador Sea by comparing model-derived $T_{\text {LSW_bnd }}$ and MOC (section 3d). On monthly time scales, $T_{\mathrm{LSW} \text { bnd }}$ is more variable than MOC over the model's temporal domain (1990-2004; not shown): the standard deviation of $T_{\mathrm{LSW} \_ \text {bnd }}(2.81 \mathrm{~Sv})$ is $\sim 40 \%$ larger than the standard deviation of the MOC (1.99Sv). There is a weak correlation between the variables $(r=-0.43)$, and only a small portion (11\%) of the total variance of $T_{\text {LSW_bnd }}$ is explained by the MOC. By comparison, there is a slightly higher correlation between $T_{\mathrm{LSW} \_ \text {bnd }}$ and $T_{\mathrm{LSW}}(r=0.56)$. The $T_{\mathrm{LSW}}$, with a standard deviation of $2.07 \mathrm{~Sv}$, explains a higher percentage (29\%) of the total variance of $T_{\mathrm{LSW} \_ \text {bnd }}$.

We find a stronger relationship between $T_{\mathrm{LSW} \_ \text {bnd }}$ and overturning in winter when both transports are intensified in the Labrador Sea (Fig. 7). There is a high correlation between the largest winter $T_{\mathrm{LSW} \text { _bnd }}$ and the winter maximum MOC $(r=-0.81)$, where the MOC explains $65 \%$ of the total $T_{\mathrm{LSW} \text { bnd }}$ variance. The correlation between the largest winter $T_{\mathrm{LSW}}$ bnd and $T_{\mathrm{LSW}}$ is also strong $(r=0.79)$ : $T_{\mathrm{LSW}}$ explains $60 \%$ of the $T_{\mathrm{LSW} \text { bnd }}$ variance. Note that none of these results is sensitive to the density limits defining LSW. Overall, owing to the fact that the boundary current transport at $53^{\circ} \mathrm{N}$ inevitably contains recirculation elements (Fig. 4; see also Zantopp et al. 2017), we conclude that $T_{\mathrm{LSW} \_ \text {bnd }}$ is not a sufficient proxy for representing the overturning variability in the

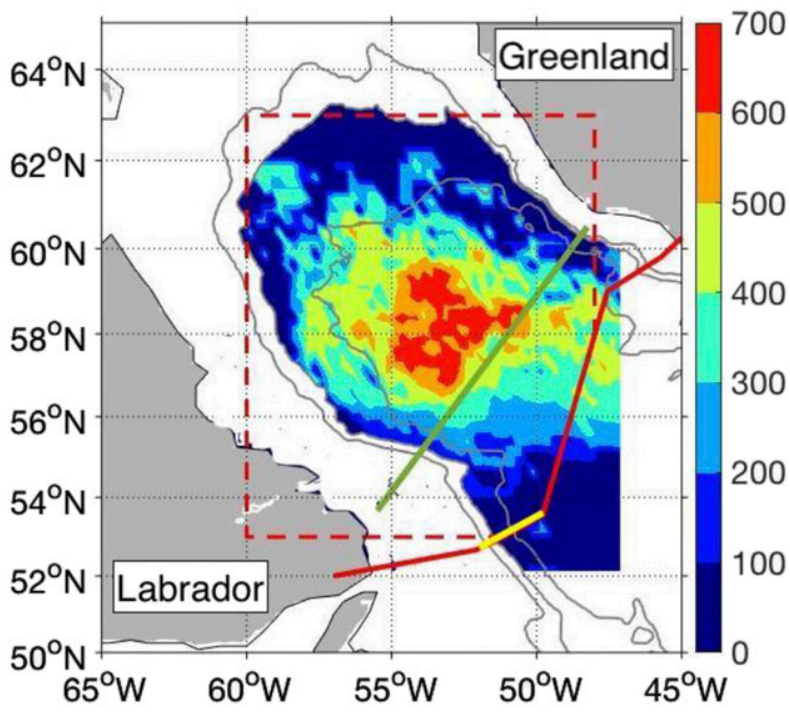

FIG. 6. Standard deviation of the winter maximum LSW layer thickness $(\mathrm{m}$ ) for 2003-13, derived from the Argo-based OA product. Gray contours indicate the 1000-, 2000-, and 3000-m isobaths. 


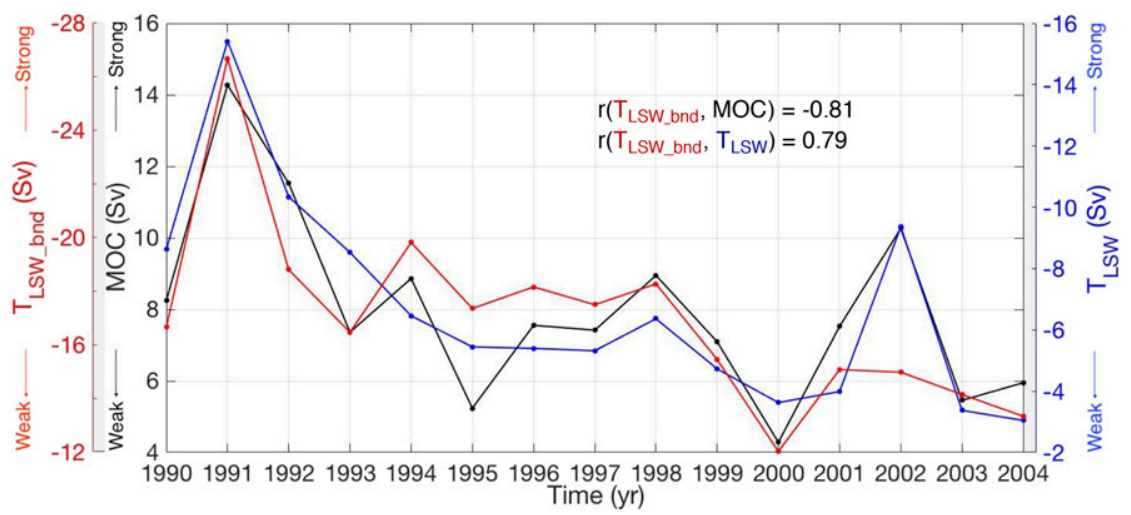

FIG. 7. MOC/ $T_{\mathrm{LSW}}$ at OSNAP West and $T_{\mathrm{LSW} \text { bnd }}$ at $53^{\circ} \mathrm{N}$, defined as the strongest transport during each winter (DJFM) for 1990-2004 from the model. Note that the $y$ axes for (right) $T_{\mathrm{LSW}}$ and (left) $T_{\mathrm{LSW} \text { bnd }}$ are reversed.

Labrador Sea. Overturning transport estimated from the transbasin OSNAP array will enable us to evaluate the linkage between boundary current transport and overturning, at least for the 2-yr period of the first OSNAP data release.

\section{c. Is density variability in the Labrador Sea a proxy for the MOC in that basin?}

Using model data, we calculate annual-mean $\sigma_{2}$ over a deep layer $(1000-2000 \mathrm{~m})$ in the Labrador Sea $\left(56^{\circ}-\right.$ $61^{\circ} \mathrm{N}, 50^{\circ}-58^{\circ} \mathrm{W}$ ), following Jackson et al. (2016). Decreasing density in the deep Labrador Sea since the mid-1990s is evident from this calculation (Fig. 8a), consistent with the observed change (e.g., Jackson et al. 2016). Figure 8a also shows that in this model, the decrease in deep Labrador Sea density lags a weakening overturning in the basin by 3 years $(r=0.54)$. These density changes are also strongly associated with LSW volume changes, with a time lag of $0-3$ years $(r=0.63$ 0.73 ; Fig. $8 \mathrm{~b}$ ). This time scale is consistent with a previous observational study (Straneo et al. 2003) on the residence time for LSW in the Labrador Sea (4-5 years). Taken together, these results imply that stronger overturning in the Labrador Sea associated with an increasing LSW volume precedes an increase in deep Labrador Sea density. However, given the relatively low correlation, we conclude that density anomalies in the Labrador Sea are only a weak proxy for the MOC in the basin. We also tested another density metric following Robson et al. (2016), where the annual-mean $\sigma_{2}$ is calculated over a broader depth range (1000-2500 m) and within a larger domain $\left(50^{\circ}-65^{\circ} \mathrm{N}, 60^{\circ}-35^{\circ} \mathrm{W}\right)$. The conclusions hold with this alternative density metric.

Previous studies have found that density changes in the Labrador Sea propagate equatorward and drive overturning variability in the subtropics (e.g., Biastoch et al.
2008; Jackson et al. 2016; Robson et al. 2016). Our results here on the relationship between overturning in the Labrador Basin and density variability in that basin do not necessarily pose a contradiction. Conventional understanding is that convection changes lead to density changes at depth in the Labrador Basin, and in time, those density changes can propagate equatorward via the deep western boundary current. The propagation of those density anomalies will produce AMOC anomalies downstream. In our model study, however, we did not find statistically significant correlations between deep Labrador Sea density changes and the MOC at $26^{\circ} \mathrm{N}$ from this 15 -yr time series. We are exploring these relationships at decadal and longer time scales in a followup study using a suite of 60-yr ocean-sea ice model simulations. In addition, the OSNAP time series together with the MOC from transbasin monitoring programs at other places in the Atlantic (e.g., RAPID Climate Change Program; Cunningham et al. 2007) will, in time, allow for a comparison of the Labrador Sea convection variability with AMOC variability downstream.

\section{d. Are subsurface temperature anomalies in the extratropical North Atlantic a proxy for the MOC in the Labrador Sea?}

We next reproduce the MOC "fingerprint" based on model data, following Zhang (2008), and examine how well it is linked to local MOC changes in the Labrador Sea. We perform an EOF analysis on annual $t_{\text {sub }}$ anomalies (relative to the 1990-2004 mean) at the model depth of $385.8 \mathrm{~m}$ in the North Atlantic $\left(20^{\circ}-65^{\circ} \mathrm{N}, 80^{\circ} \mathrm{W}-0^{\circ}\right)$. As in Zhang (2008), the first EOF component accounts for $33.6 \%$ of the total $t_{\text {sub }}$ variance and is associated with a distinctive "dipole" pattern (not shown), and the PC1 of the $t_{\text {sub }}$ time series shows a warming for $t_{\text {sub }}$ in the 

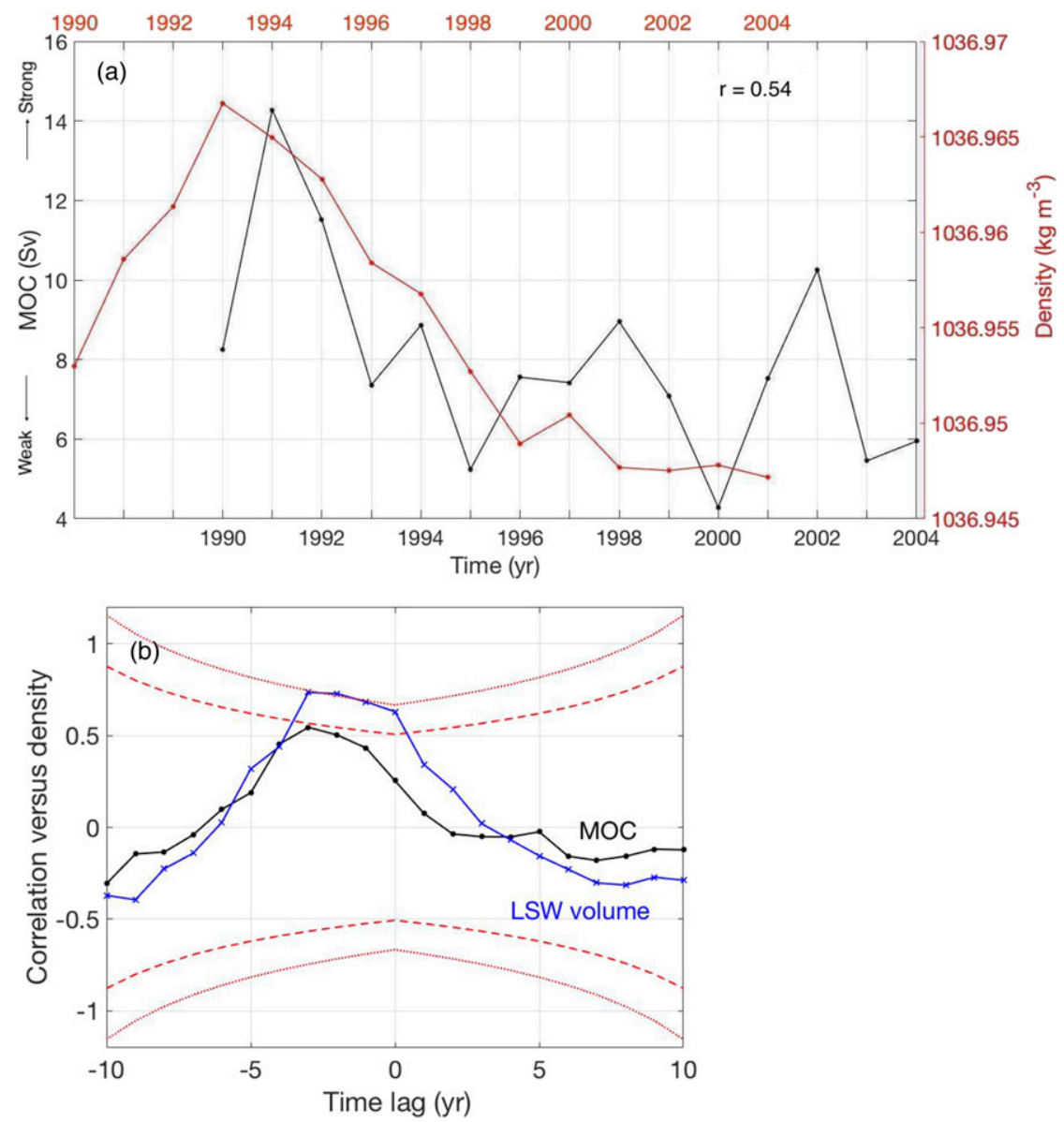

FIG. 8. (a) Winter (DJFM) maximum MOC at OSNAP West and annual-mean potential density (referenced to $2000 \mathrm{dbar}$ ) averaged over $1000-2000 \mathrm{~m}$ in the Labrador Sea $\left(50^{\circ}-58^{\circ} \mathrm{W}\right.$, $56^{\circ}-61^{\circ} \mathrm{N}$ ), all from the model. The annual density time series is shifted backward by 3 years. (b) The lead-lag relationship among density, MOC, and LSW volume. Dashed and dotted red lines indicate the $95 \%$ and $99 \%$ confidence intervals, respectively. Negative lags show where the deep Labrador Sea density is lagging the other variables.

SPG from the early 1990 s to the early 2000 s. Using this metric with model output, we find that a strengthening of the MOC in the Labrador Sea leads a colder $t_{\text {sub }}$ in the SPG by 3 years $(r=-0.54$; Fig. 9$)$. Such a relationship can be understood causally: over interannual time scales, stronger overturning in the Labrador Sea is associated with stronger deep convection that actively removes heat from the water column. The relationship between convection and the subsurface temperature is consistent with previous observational studies on the upper ocean temperature and heat content variations in the region (e.g., Yashayaev and Loder 2009; Li et al. 2015). Overall, given the relatively low correlation, we conclude that the leading mode of $t_{\text {sub }}$ anomalies is a weak proxy for the MOC in the Labrador Sea.
Previous modeling studies have suggested that a strengthening MOC at $\sim 40^{\circ} \mathrm{N}$ in the Atlantic is associated with a warmer SPG over decadal and longer time scales (Zhang 2008; Lohmann et al. 2009a,b; Robson et al. 2012). By comparison, we find that a colder $t_{\text {sub }}$ in the SPG precedes a strengthening MOC at $40^{\circ} \mathrm{N}$ by a few years $(r=-0.65)$ and that there is not a statistically significant correlation between $t_{\text {sub }}$ and the MOC at $26^{\circ} \mathrm{N}$. Nevertheless, the relationships we find do not necessarily contradict those modeling studies because they are focused on longer-term variability, and our analysis is valid for interannual time scales. In addition, these models may differ in how much the SPG heat content is affected by the horizontal gyre circulations, thus impacting the relationship between $t_{\text {sub }}$ and the MOC (Robson et al. 2012; Piecuch et al. 2017). 


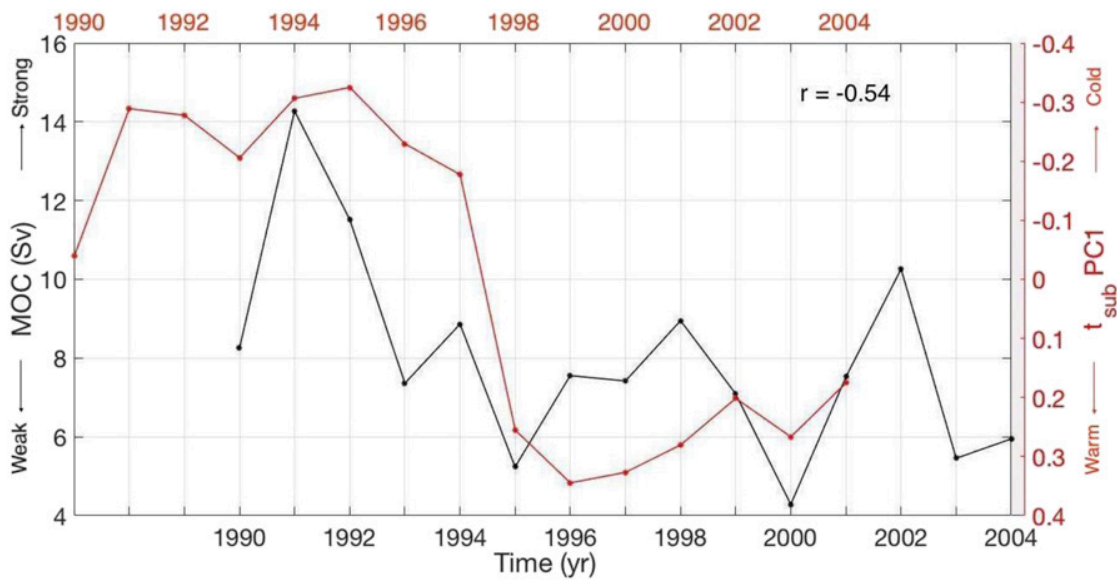

FIG. 9. Winter (DJFM) maximum MOC at OSNAP West (black) and $t_{\text {sub }} \mathrm{PC1}$ (red) from the model; $t_{\text {sub }}$ PC1 is shifted backward by 3 years, and its $y$ axis (right) is reversed.

\section{LSW volume and the MOC in the Labrador Sea}

Relying on direct measures, rather than proxies, we use model data to analyze how LSW volume is linked to the local MOC in the Labrador Sea and how changes in LSW volume and MOC respond to local atmospheric forcing over the region. All model relationships examined in the following section will be examined with OSNAP observations when available, albeit for a shorter time scale.

\section{a. $L S W$ volume and $M O C$}

The annual LSW volume and MOC (and $T_{\mathrm{LSW}}$ ) time series are compared in Fig. 10. These time series are constructed with the largest monthly LSW volume and the strongest transport during each winter (DJFM) for 1990-2004. The correlation between LSW volume and MOC is 0.61 with zero lag. The MOC was intensified in 1990-95, with an average magnitude $15 \%$ above the mean of all winter maxima, which coincides with the period of strong deep convection with a larger LSW volume. There is also a strong correlation between LSW volume and $T_{\mathrm{LSW}}$, also with zero lag $(r=-0.70)$. The export of LSW from the Labrador Basin increased in the early 1990s, when the average magnitude for 1990-95 is $37 \%$ below the mean of the winter minima ( $T_{\mathrm{LSw}}$ values are negative). Therefore, over interannual time scales, an increase in the LSW volume is associated with a nearly simultaneous increase in overturning and LSW export.

\section{b. Relationship to the atmospheric forcing}

Surface heat loss in the Labrador Sea during severe winters is a major factor contributing to LSW production over a range of time scales, which can be largely characterized by the winter North Atlantic Oscillation (NAO) index (e.g., Marshall et al. 1998; Lazier et al. 2002;

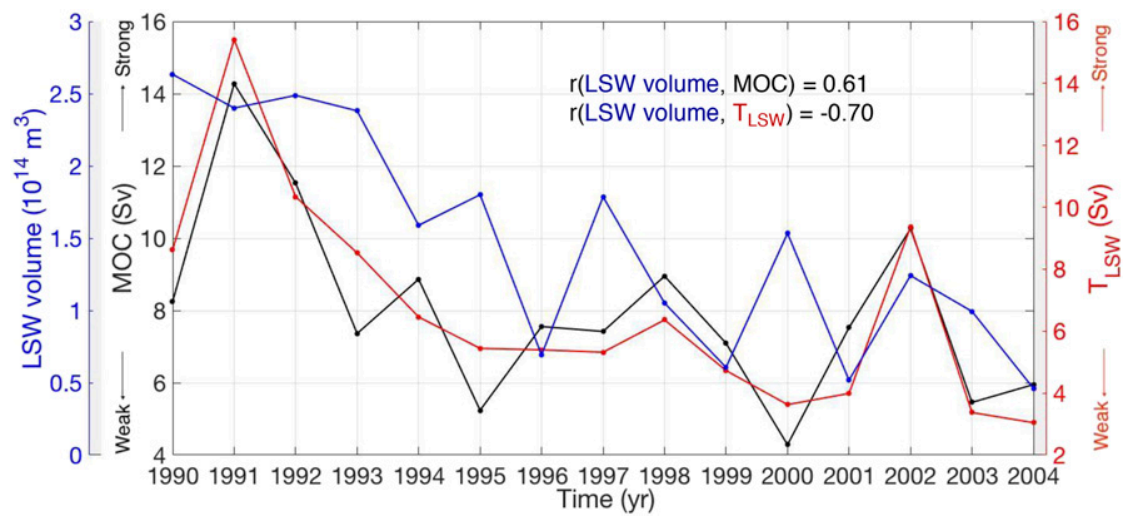

FIG. 10. LSW volume (blue), the MOC (black), and $T_{\mathrm{LSW}}$ (red) time series from the model, defined as the winter (DJFM) maximum volume or the strongest transport. The $y$ axis for $T_{\mathrm{LSW}}$ (right) is reversed. 


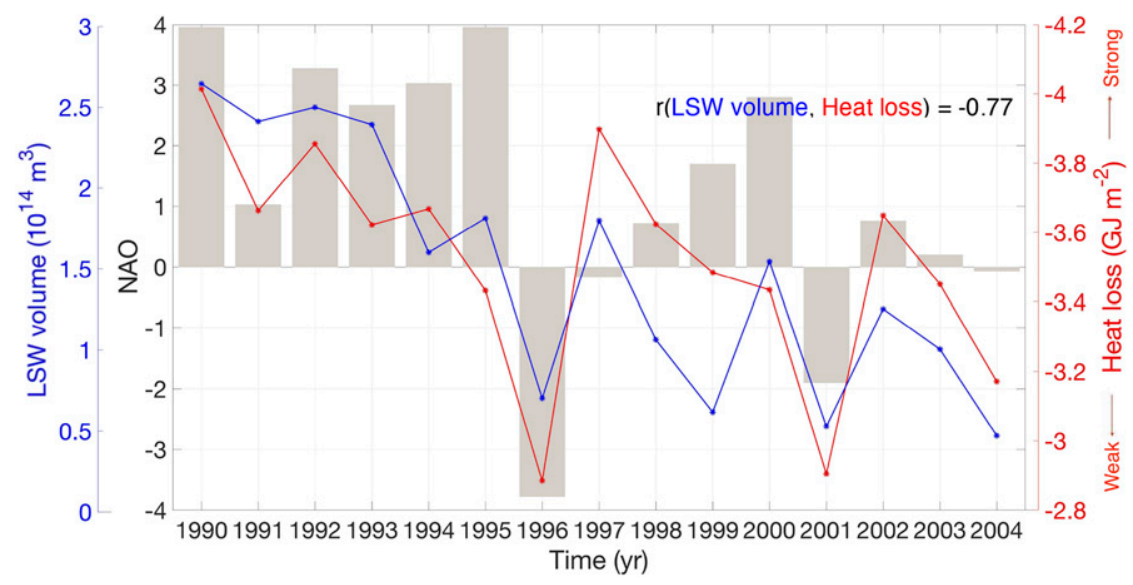

FIG. 11. Winter (October-March) accumulated heat loss (red) and winter (DJFM) maximum LSW volume (blue) in the Labrador Basin. Station-based winter NAO index is indicated with gray bars (Hurrell et al. 2016). The $y$ axis for the heat loss (right) is reversed.

Yashayaev 2007). We converted the surface heat flux to heat loss accumulated during each cooling season (October-March) by summing all negative surface heat fluxes (from ocean to the atmosphere) from October of one year to March of the next year (see also Yashayaev and Loder 2009). We refer to this accumulation of "equivalent" heat loss as the accumulated heat loss. Because there are no model data before 1990, we used the heat loss from October to December in 1990 instead for 1989 in order to get the accumulated heat loss for the winter of 1990.

Overall, there is a strong and direct impact of atmospheric forcing (cooling) on LSW volume over interannual time scales ( $r=-0.77$; Fig. 11). The early 1990s were characterized by a period of harsh winters with enhanced heat loss, which resulted in the successive production of large LSW volumes in the Labrador Sea-a scenario consistent with observations (e.g., Lazier et al. 2002). The linkage between accumulated heat loss and LSW volume weakened in the late 1990s, as the NAO shifted away from a persistently strong and positive phase (1990-95) to a period with weak fluctuations in the phase (Fig. 11). This weakened linkage is attributed to (i) the fact that the NAO does not capture all of the significant variations in atmospheric forcing over the North Atlantic (Hurrell et al. 2006) and (ii) preconditioning in the Labrador Sea, which likely plays an important role in deep water formation (Yashayaev 2007; Våge et al. 2009).

The relationship between overturning in the Labrador Sea and local atmospheric forcing is modest on interannual time scales. The correlation coefficient between the accumulated heat loss and MOC $\left(T_{\mathrm{LSw}}\right)$ is -0.58 (0.51) with zero lag. Nevertheless, the concomitant changes from the early 1990s to the late 1990s are still evident and consistent with that observed (e.g., Lazier et al. 2002; Yashayaev 2007): the early 1990s were a period of strong overturning along with enhanced heat loss, compared to that in the late 1990s through the early 2000s. We note that our analysis cannot rule out a strong and lagged response of the variability in the Labrador Sea to atmospheric forcing on time scales longer than a couple of years (e.g., Ortega et al. 2017).

\section{Summary}

In this study, we evaluate proxies for LSW formation and overturning in the Labrador Sea. Our results reveal the limitations of those proxies in providing estimates for the strength of LSW formation and local overturning changes and, therefore, highlight the necessity of sustaining direct measurements in the subpolar region. Using model output from a highresolution OGCM, it is shown that a large LSW volume in the Labrador Sea, formed in response to intensified atmospheric cooling, is associated with a strengthening of the local overturning and increasing export of LSW out of the basin. Also, an increase in the density of the deep waters in the Labrador Sea and a cooling of the subsurface waters in the SPG lag the overturning by 3 years.

The relationship between LSW volume changes and MOC variations in the model is modest on interannual time scales $(r=0.61)$. But there are concomitant weakening trends in LSW formation and transport as well as the MOC in the Labrador Sea from the early 1990 s to the early 2000s. Thus, the response of overturning changes in the Labrador Sea to changes in 
LSW volume and to atmospheric forcing may act over longer (i.e., decadal to multidecadal) time scales. Our analysis cannot reveal that response, owing to a limited temporal span of the model output. It is noteworthy that a similar relationship is found using output from an eddy-permitting ocean-sea ice model over a longer time period of 1961-2004 ( $r=0.52$, in which the LSW volume changes are leading by 1 year). In a follow-up study, we rely on 60-yr ocean-sea ice model simulations varying in resolution to further diagnose the local and downstream relationships between LSW formation and overturning circulations in the North Atlantic over decadal time scales.

There was a widespread strong cooling in the subpolar North Atlantic during recent winters, with clear signatures of enhanced deep ocean convection in the Labrador Sea and the Irminger Sea (de Jong and de Steur 2016; Yashayaev and Loder 2017). Our estimates of the LSW volume from the OA product reveal $>40 \%$ increase in the volume in the Labrador Sea for the three successive winters from 2014 to 2016, compared to the 2003-13 mean volume (not shown). The OSNAP measurements will provide insight into the impact of those strong LSW formation events on overturning in the subpolar region.

We stress that the focus of our analysis and discussions is on the relationship among local convection, transport, and overturning measures - in a region north of the OSNAP line in the Labrador Sea. This is primarily to understand the relationship between local LSW formation and the net LSW export out of the basin. Since LSW is also formed in the Irminger Sea (Pickart et al. 2003; de Jong et al. 2012), further investigation is needed to study the relationship between LSW volume in the entire SPG and overturning changes.

Acknowledgments. FL and MSL gratefully acknowledge the support of the Physical Oceanography Program of the National Science Foundation (NSF-OCE-1259102 and NSF-OCE-12-59013). FL thanks Sijia Zou for helpful discussions, and MSL thanks Ric Williams for insightful comments on an early draft of this paper. The CTD data on the AR7W sections were collected during Fisheries and Oceans Canada's (DFO's) annual survey under its Atlantic Zone Off-shelf Monitoring Program (AZOMP; http://www.bio.gc.ca/science/ monitoring-monitorage/azomp-pmzao/azomp-pmzao-en. php). Argo data were collected and made freely available by the International Argo Program and the national programs that contribute to it (http://www.argo.ucsd.edu, http://argo.jcommops.org). The Argo Program is part of the Global Ocean Observing System (https://doi.org/ 10.17882/42182).

\section{REFERENCES}

Beckmann, A., and R. Döscher, 1997: A method for improved representation of dense water spreading over topography in geopotential-coordinate models. J. Phys. Oceanogr., 27, 581-591, https://doi.org/10.1175/1520-0485(1997)027<0581: AMFIRO $>2.0 . \mathrm{CO} ; 2$.

Biastoch, A., C. W. Böning, J. Getzlaff, J.-M. Molines, and G. Madec, 2008: Causes of interannual-decadal variability in the meridional overturning circulation of the midlatitude North Atlantic Ocean. J. Climate, 21, 6599-6615, https://doi.org/ 10.1175/2008JCLI2404.1.

Bingham, R. J., C. W. Hughes, V. Roussenov, and R. G. Williams, 2007: Meridional coherence of the North Atlantic meridional overturning circulation. Geophys. Res. Lett., 34, L23606, https://doi.org/10.1029/2007GL031731.

Böning, C. W., M. Rhein, J. Dengg, and C. Dorow, 2003: Modeling CFC inventories and formation rates of Labrador Sea Water. Geophys. Res. Lett., 30, 1050, https://doi.org/10.1029/2002GL014855.

, M. Scheinert, J. Dengg, A. Biastoch, and A. Funk, 2006: Decadal variability of subpolar gyre transport and its reverberation in the North Atlantic overturning. Geophys. Res. Lett., 33, L21S01, https://doi.org/10.1029/2006GL026906.

Brauch, J. P., and R. Gerdes, 2005: Response of the northern North Atlantic and Arctic oceans to a sudden change of the North Atlantic Oscillation. J. Geophys. Res., 110, C11018, https://doi.org/ 10.1029/2004JC002436.

Bretherton, F. P., R. E. Davis, and C. B. Fandry, 1976: A technique for objective analysis and design of oceanographic experiments applied to MODE-73. Deep-Sea Res. Oceanogr. Abstr., 23, 559-582, https://doi.org/10.1016/0011-7471(76)90001-2.

Cunningham, S. A., and Coauthors, 2007: Temporal variability of the Atlantic meridional overturning circulation at $26.5^{\circ} \mathrm{N}$. Science, 317, 935-938, https://doi.org/10.1126/science.1141304.

de Jong, M. F., and L. de Steur, 2016: Strong winter cooling over the Irminger Sea in winter 2014-2015, exceptional deep convection, and the emergence of anomalously low SST. Geophys. Res. Lett., 43, 7106-7113, https://doi.org/10.1002/ 2016 GL069596.

, H. M. van Aken, K. Våge, and R. S. Pickart, 2012: Convective mixing in the central Irminger Sea: 2002-2010. Deep-Sea Res. I, 63, 36-51, https://doi.org/10.1016/j.dsr.2012.01.003.

- A. S. Bower, and H. H. Furey, 2016: Seasonal and interannual variations of Irminger ring formation and boundary-interior heat exchange in FLAME. J. Phys. Oceanogr., 46, 1717-1734, https://doi.org/10.1175/JPO-D-15-0124.1.

Dengler, M., J. Fischer, F. A. Schott, and R. Zantopp, 2006: Deep Labrador Current and its variability in 1996-2005. Geophys. Res. Lett., 33, L21S06, https://doi.org/10.1029/2006GL026702.

Eden, C., and J. Willebrand, 2001: Mechanism of interannual to decadal variability of the North Atlantic circulation. J. Climate, 14, 2266-2280, https://doi.org/10.1175/1520-0442 (2001) $014<2266:$ MOITDV > 2.0.CO;2.

, and C. W. Böning, 2002: Sources of eddy kinetic energy in the Labrador Sea. J. Phys. Oceanogr., 32, 3346-3363, https://doi.org/ 10.1175/1520-0485(2002)032<3346:SOEKEI $>2.0 . C O ; 2$.

Fischer, J., and F. A. Schott, 2002: Labrador Sea water tracked by profiling floats-From the boundary current into the open North Atlantic. J. Phys. Oceanogr., 32, 573-584, https://doi.org/ 10.1175/1520-0485(2002)032<0573:LSWTBP $>2.0 . C O ; 2$

, - _ , and M. Dengler, 2004: Boundary circulation at the exit of the Labrador Sea. J. Phys. Oceanogr., 34, 1548-1570, https:// doi.org/10.1175/1520-0485(2004)034<1548:BCATEO>2.0.CO;2. 
—_, M. Visbeck, R. Zantopp, and N. Nunes, 2010: Interannual to decadal variability of outflow from the Labrador Sea. Geophys. Res. Lett., 37, L24610, https://doi.org/10.1029/ 2010GL045321.

Gary, S. F., M. S. Lozier, C. W. Böning, and A. Biastoch, 2011: Deciphering the pathways for the deep limb of the meridional overturning circulation. Deep-Sea Res. II, 58, 1781-1797, https://doi.org/10.1016/j.dsr2.2010.10.059.

Getzlaff, J., C. W. Böning, C. Eden, and A. Biastoch, 2005: Signal propagation related to the North Atlantic overturning. Geophys. Res. Lett., 32, L09602, https://doi.org/10.1029/ 2004GL021002.

Hadfield, R. E., N. C. Wells, S. A. Josey, and J. J.-M. Hirschi, 2007: On the accuracy of North Atlantic temperature and heat storage fields from Argo. J. Geophys. Res., 112, C01009, https://doi.org/10.1029/2006JC003825.

Haine, T., and Coauthors, 2008: North Atlantic deep water formation in the Labrador Sea, recirculation through the subpolar gyre, and discharge to the subtropics. Arctic-Subarctic Ocean Fluxes: Defining the Role of the Northern Seas in Climate, R. R. Dickson et al., Eds., Springer Netherlands, 653-701.

Hall, M. M., D. J. Torres, and I. Yashayaev, 2013: Absolute velocity along the AR7W section in the Labrador Sea. Deep-Sea Res., 72, 72-87, https://doi.org/10.1016/j.dsr.2012.11.005.

Holte, J., and F. Straneo, 2017: Seasonal overturning of the Labrador Sea as observed by Argo floats. J. Phys. Oceanogr., 47, 2531-2543, https://doi.org/10.1175/JPO-D-17-0051.1.

, L. D. Talley, J. Gilson, and D. Roemmich, 2017a: Argo mixed layers. Scripps Institution of Oceanography, University of California, San Diego, accessed 14 February 2017, http:// mixedlayer.ucsd.edu.

,,,--- , and 2017b: An Argo mixed layer climatology and database. Geophys. Res. Lett., 44, 5618-5626, https:// doi.org/10.1002/2017GL073426.

Hurrell, J. W., and NCAR Staff (Eds.), Last modified 16 Aug 2016. "The Climate Data Guide: Hurrell North Atlantic Oscillation (NAO) Index (station-based)." Accessed 5 October 2016; https://climatedataguide.ucar.edu/climate-data/hurrell-northatlantic-oscillation-nao-index-station-based.

— dictability: A CLIVAR perspective. J. Climate, 19, 5100-5121, https://doi.org/10.1175/JCLI3902.1.

Jackson, L. C., K. A. Peterson, C. D. Roberts, and R. A. Wood, 2016: Recent slowing of Atlantic overturning circulation as a recovery from earlier strengthening. Nature, 9, 518-522, https://doi.org/10.1038/ngeo2715.

Kalnay, E., and Coauthors, 1996: The NCEP/NCAR 40-Year Reanalysis Project. Bull. Amer. Meteor. Soc., 77, 437-471, https:// doi.org/10.1175/1520-0477(1996)077<0437:TNYRP>2.0.CO;2.

Kieke, D., and I. Yashayaev, 2015: Studies of Labrador Sea Water formation and variability in the subpolar North Atlantic in the light of international partnership and collaboration. Prog. Oceanogr., 132, 220-232, https://doi.org/ 10.1016/j.pocean.2014.12.010.

Kuhlbrodt, T., A. Griesel, M. Montoya, A. Levermann, M. Hofmann, and S. Rahmstorf, 2007: On the driving processes of the Atlantic meridional overturning circulation. Rev. Geophys., 45, RG2001, https://doi.org/10.1029/ 2004RG000166.

Lavender, K. L., R. E. Davis, and W. B. Owens, 2000: Mid-depth recirculation observed in the interior Labrador and Irminger seas by direct velocity measurements. Nature, 407, 66-69, https://doi.org/10.1038/35024048
— W. B. Owens, and R. E. Davis, 2005: The mid-depth circulation of the subpolar North Atlantic Ocean as measured by subsurface floats. Deep-Sea Res. I, 52, 767-785, https://doi.org/ 10.1016/j.dsr.2004.12.007.

Lazier, J. R., 1980: Oceanographic conditions at ocean weather ship Bravo, 1964-1974. Atmos.-Ocean, 18, 227-238, https:// doi.org/10.1080/07055900.1980.9649089.

_ - R. Hendry, A. Clarke, I. Yashayaev, and P. Rhines, 2002: Convection and restratification in the Labrador Sea, 19902000. Deep-Sea Res. I, 49, 1819-1835, https://doi.org/10.1016/ S0967-0637(02)00064-X.

Li, F., Y.-H. Jo, X.-H. Yan, and W. T. Liu, 2015: Varying temperature and heat content signatures in the central Labrador Sea at different layers and timescales. Deep-Sea Res. I, 103, 114-124, https://doi.org/10.1016/j.dsr.2015.04.012.

— M. S. Lozier, and W. E. Johns, 2017: Calculating the meridional volume, heat, and freshwater transports from an observing system in the subpolar North Atlantic: Observing system simulation experiment. J. Atmos. Oceanic Technol., 34, 1483-1500, https://doi.org/10.1175/JTECH-D-16-0247.1.

Locarnini, R. A., and Coauthors, 2013: Temperature. Vol. 1, World Ocean Atlas 2013, S. Levitus, Ed., NOAA Atlas NESDIS 73, $40 \mathrm{pp}$.

Lohmann, K., H. Drange, and M. Bentsen, 2009a: A possible mechanism for the strong weakening of the North Atlantic subpolar gyre in the mid-1990s. Geophys. Res. Lett., 36, L15602, https://doi.org/10.1029/2009GL039166.

$\longrightarrow,-$, and $-2009 \mathrm{~b}$ : Response of the North Atlantic subpolar gyre to persistent North Atlantic Oscillation like forcing. Climate Dyn., 32, 273-285, https://doi.org/10.1007/s00382-008-0467-6.

Lozier, M. S., 2012: Overturning in the North Atlantic. Annu. Rev. Mar. Sci., 4, 291-315, https://doi.org/10.1146/annurevmarine-120710-100740.

— , V. Roussenov, M. S. C. Reed, and R. G. Williams, 2010: Opposing decadal changes for the North Atlantic meridional overturning circulation. Nat. Geosci., 3, 728-734, https://doi.org/ 10.1038/ngeo947.

_ S. F. Gary, and A. S. Bower, 2013: Simulated pathways of the overflow waters in the North Atlantic: Subpolar to subtropical export. Deep-Sea Res. II, 85, 147-153, https://doi.org/10.1016/ j.dsr2.2012.07.037.

_ - and Coauthors, 2017: Overturning in the subpolar North Atlantic program: A new international ocean observing system. Bull. Amer. Meteor. Soc., 98, 737-752, https://doi.org/ 10.1175/BAMS-D-16-0057.1.

Marshall, J., and Coauthors, 1998: The Labrador Sea deep convection experiment. Bull. Amer. Meteor. Soc., 79, 2033-2058, https://doi.org/10.1175/1520-0477(1998)079<2033:TLSDCE $>2.0$. $\mathrm{CO} ; 2$.

Mercier, H., and Coauthors, 2015: Variability of the meridional overturning circulation at the Greenland-Portugal OVIDE section from 1993 to 2010. Prog. Oceanogr., 132, 250-261, https://doi.org/10.1016/j.pocean.2013.11.001.

Myers, P. G., and N. Kulan, 2012: Changes in the deep western boundary current at $53^{\circ}$ N. J. Phys. Oceanogr., 42, 1207-1216, https://doi.org/10.1175/JPO-D-11-090.1.

Ortega, P., J. Robson, R. T. Sutton, and M. B. Andrews, 2017 Mechanisms of decadal variability in the Labrador Sea and the wider North Atlantic in a high-resolution climate model. Climate Dyn., 49, 2625-2647, https://doi.org/10.1007/ s00382-016-3467-y.

Pacanowski, R. C., 1996: MOM 2 documentation user's guide and reference manual. GFDL Ocean Tech. Rep. 3.2, 329 pp. 
Palter, J. B., M. S. Lozier, and K. L. Lavender, 2008: How does Labrador Sea Water enter the deep western boundary current? J. Phys. Oceanogr., 38, 968-983, https://doi.org/ 10.1175/2007JPO3807.1.

Pickart, R. S., and M. A. Spall, 2007: Impact of Labrador Sea convection on the North Atlantic meridional overturning circulation. J. Phys. Oceanogr., 37, 2207-2227, https://doi.org/ 10.1175/JPO3178.1.

— , D. J. Torres, and R. A. Clarke, 2002: Hydrography of the Labrador Sea during active convection. J. Phys. Oceanogr., 32, 428-457, https://doi.org/10.1175/1520-0485(2002)032<0428: HOTLSD $>2.0 . \mathrm{CO} ; 2$.

_ , F. Straneo, and G. W. K. Moore, 2003: Is Labrador Sea Water formed in the Irminger basin? Deep-Sea Res. I, 50, 23-52, https://doi.org/10.1016/S0967-0637(02)00134-6.

Piecuch, C. G., R. M. Ponte, C. M. Little, M. W. Buckley, and I. Fukumori, 2017: Mechanisms underlying recent decadal changes in subpolar North Atlantic Ocean heat content. J. Geophys. Res. Oceans, 122, 7181-7197, https://doi.org/ 10.1002/2017JC012845.

Robson, J., R. Sutton, K. Lohmann, D. Smith, and M. D. Palmer, 2012: Causes of the rapid warming of the North Atlantic Ocean in the mid-1990s. J. Climate, 25, 4116-4134, https://doi.org/10.1175/ JCLI-D-11-00443.1.

_- P. Ortega, and R. Sutton, 2016: A reversal of climatic trends in the North Atlantic since 2005. Nature, 9, 513-517, https:// doi.org/10.1038/ngeo2727.

Stramma, L., D. Kieke, M. Rhein, F. Schott, I. Yashayaev, and K. P. Koltermann, 2004: Deep water changes at the western boundary of the subpolar North Atlantic during 1996 to 2001. Deep-Sea Res. I, 51, 1033-1056, https://doi.org/10.1016/j.dsr.2004.04.001.

Straneo, F., R. S. Pickart, and K. Lavender, 2003: Spreading of Labrador Sea Water: An advective-diffusive study based on Lagrangian data. Deep-Sea Res. I, 50, 701-719, https://doi.org/ 10.1016/S0967-0637(03)00057-8.

Talley, L. D., and M. S. McCartney, 1982: Distribution and circulation of Labrador Sea Water. J. Phys. Oceanogr., 12,
1189-1205, https://doi.org/10.1175/1520-0485(1982)012<1189: DACOLS $>2.0 . \mathrm{CO} ; 2$.

Våge, K., and Coauthors, 2009: Surprising return of deep convection to the subpolar North Atlantic Ocean in winter 2007-2008. Nat. Geosci., 2, 67-72, https://doi.org/10.1038/ ngeo382.

Yashayaev, I., 2007: Hydrographic changes in the Labrador Sea, 1960-2005. Prog. Oceanogr., 73, 242-276, https://doi.org/ 10.1016/j.pocean.2007.04.015.

— , and J. W. Loder, 2009: Enhanced production of Labrador Sea Water in 2008. Geophys. Res. Lett., 36, L01606, https://doi.org/ 10.1029/2008GL036162.

— , and —, 2016: Recurrent replenishment of Labrador Sea Water and associated decadal-scale variability. J. Geophys. Res. Oceans, 121, 8095-8114, https://doi.org/10.1002/2016JC012046.

- , and - 2017: Further intensification of deep convection in the Labrador Sea in 2016. Geophys. Res. Lett., 44, 1429-1438, https://doi.org/10.1002/2016GL071668.

- M. Bersch, and H. M. van Aken, 2007: Spreading of the Labrador Sea Water to the Irminger and Iceland basins. Geophys. Res. Lett., 34, L10602, https://doi.org/10.1029/2006GL028999.

Zantopp, R., J. Fischer, M. Visbeck, and J. Karstensen, 2017: From interannual to decadal: 17 years of boundary current transports at the exit of the Labrador Sea.J. Geophys. Res. Oceans, 122, 1724-1748, https://doi.org/10.1002/2016JC012271.

Zhang, R., 2008: Coherent surface-subsurface fingerprint of the Atlantic meridional overturning circulation. Geophys. Res. Lett., 35, L20705, https://doi.org/10.1029/2008GL035463.

_ 2010: Latitudinal dependence of Atlantic meridional overturning circulation (AMOC) variations. Geophys. Res. Lett., 37, L16703, https://doi.org/10.1029/2010GL044474.

Zou, S., and M. S. Lozier, 2016: Breaking the linkage between Labrador Sea Water production and its advective export to the subtropical gyre. J. Phys. Oceanogr., 46, 2169-2182, https:// doi.org/10.1175/JPO-D-15-0210.1.

Zweng, M. M., and Coauthors, 2013: Salinity. Vol. 2, World Ocean Atlas 2013, S. Levitus, Ed., NOAA Atlas NESDIS 74, 39 pp. 